\title{
IMPLEMENTASI APLIKASI MOBILE TREVEL GUIDE DI SEKTOR KOTA SEMARANG
}

\author{
Brian surya A.P ${ }^{1}$, Dwi Agus Diartono ${ }^{2}$ \\ Semarang, Indonesia ${ }^{1}$, Semarang, Indonesia ${ }^{2}$ \\ e-mail: 'briansurya71@gmail.com, ${ }^{2}$ dwieagus@edu.unisbank.ac.id
}

\begin{abstract}
ABSTRAK
LBS (location based service) adalah layanan informasi yang dapat diakses melalui mobile device dengan memanfaatkan teknologi GPS, sistem $L B S$ ini dapat mengetahui posisi berdasarkan titik geografis dari lokasi pengguna dan lokasi yang akan dituju. Dalam sistem yang dibagun oleh peneliti yaitu implementasi aplikasi mobile trevel guide untuk sektor kota semarang. Dengan sistem ini tentunya dapat mempermudah para wisatawan untuk menemukan sektor parwisata yang ingin di tujunya dan sesuai dengan minat para wisatawan. Dengan menggunakan bantuan teknologi GPS diharapkan para wisatawan dapat dipermudah serta dapat mempersingkat waktu saat melakukan perjalanan wisata sesuai yang di harapkan wisatawan. Didalam pembuatan sistem ini menggunakan bahasa pemograman Dart serta menggunakan framework Flutter dengan perangkat lunak yang di gunakan adalah VS Code, Android SDK, Android Virtual Device serta Browser untuk manage firebase. Sistem berbasis mobile aplication, terdapat beberapa vitur menu untuk mempermudah jalannya sistem.
\end{abstract}

Kata Kunci: LBS, GPS, Pariwisata, Aplikasi mobile

\begin{abstract}
LBS (location based service) is the mobile device accessible through the mobile device using GPS technology, the LBS system can find out position based on the geographic location of the user location and the location to which it is located. In a system designed by researchers, it is the development of the location based service application for information and locating tourist locations in the city of semarang. An advantage of this system is that it makes it easier for tourists to locate tourist spots according to user interest. This system uses GPS technology to help us make it easier for tourists and cut the time when they want to make the trip. The building of this system uses the programmed dart language and uses the framework flutter with software used are vscode, the SDK android, the virtual device and browser for manage firebase. It is a mobile aplication system which commissions several menu features to facilitate the system's path.
\end{abstract}

Keywords = LBS, GPS, Tourism, Mobile Applications 


\section{PENDAHULUAN}

Pariwisata adalah salah satu sektor yang dapat di andalkan untuk menjadi penunjang pertumbuhan perekonomian di daerah tertentu. Kota semarang memiliki ragam sektor pariwisata yang cukup potensial untuk menunjang pertumbuhan perekonomian daerahnya. Sektor pariwisata di kota semarang pada tahun ini berkembang pesat terbukti dari munculnya wisata-wisata baru yang menarik minat wisatawan di antaranya adalah kampung pelangi yang bertempat di jalan Dr. Sutomo kecamatan Semarang selatan, bukan hanya sektor wisata baru saja di sektor wisata lamapun (kota lama) di rombak sedemikian rupa sehingga menarik rasa penasaran para wisatawan. Seiring dengan perkembangan ilmu dan teknologi, muncul suatu perkembangan teknologi yaitu GPS yang bertujuan untuk mengetahui letak tempat yang akan dituju dan mengetahui keberadaan pengguna dengan bantuan sinyal satelit. GPS dapat memberikan informasi yang tepat dan akurat mengenai posisi, kecepatan, arah dan waktu. Dalam upaya memudahkan wisatawan domestik maupun mancanegara untuk mencari lokasi tempat wisata di kota semarang, maka akan di rancang sebuah aplikasi yang bertujuan mempermudah wisatawan dalam mencari obyek wisata, dimana nantinya aplikasi tersebut dapat menampilkan rute tercepat sehingga dapat bermanfaat bagi pengguna aplikasi tersebut.

\section{TINJAUAN PUSTAKA}

Menurut Brian Dani Wiradita (2013) [1], meskipun saat ini pencarian sudah dilakukan secara online menggunakan peta serta website wisatawan masih akan sering mengalami kesulitan mencari tempat atau fasilitas wisata yang tepat, dan juga sedikit tidak efisien karena membutuhkan banyak waktu. Oleh karena itu, Brian Dani Wiradita membangun aplikasi pada perangkat mobile untuk memudahkan pencarian informasi yang dibutuhkan. Aplikasi pada dasarnya akan menyajikan informasi tentang tempat-tempat wisata di Kabupaten Gunungkidul dan juga akan menyediakan rute untuk mencapai tempat-tempat wisata dengan menggunakan GPS (Global Positioning System). Sedangkan Menurut penelitian Muhammad Amin (2012) [2], informasi mengenai obyek pariwisata beserta berita pariwisata dibutuhkan oleh calon wisatawan. Informasi pariwisata yang disediakan oleh website Dinas Pariwisata Sumatera Barat yang ada saat ini dikelola sepenuhnya oleh admin dan hanya admin yang dapat memberikan informasi mengenai pariwisata Sumatera Barat, sehingga informasi yang didapatkan terbatas pada inputan admin dan tidak aktual. Untuk mengatasi permasalahan tersebut dibuat aplikasi portal informasi pariwisata, dengan penerapan User Generated Content (UGC/UCC) yang membantu pengguna untuk menambahkan ataupun mengubah informasi mengenai berita wisata, cerita rakyat, tempat wisata, acara wisata, tips dan trik wisata, dan review tempat wisata. Pengembangan aplikasi ini menggunakan metode Rational
Unified Process, dengan bahasa pemodelan Unified Modeling Language. Tahap implementasinya menggunakan bahasa pemrograman Ruby yang dikembangkan dengan framework Ruby on Rails.

Melihat dari penelitian-penelitian di atas, di temukan berbagai ide-ide yang menginspirasi penulis dalam membuat penelitiannya, dengan memanfaatkan vitur teknologi Global Positioning System maka sistem di harapkan akan dapat menunjang kebutuhan user nantinya. Selain itu yang membuat penelitian ini berbeda dengan penelitian - penelitian terdahulu yaitu, penelitian ini di lengkapi dengan algoritma Dijkstra serta pada penelitian ini hanya akan memfokuskan pada sektor wisata, dengan melibatkan seluruh sektor wisata yang ada dikota semarang. Untuk pembangunan aplikasi penulis menggunakan VS Code dan tools yang digunakan untuk pembangunan sistem adalah UML serta menggunakan data based Firebase.

\section{METODE YANG DIUSULKAN}

3.1 Metode Pengumpulan Data

Sumber data yang digunakan dalam penelitian ini adalah :

a. Data Primer

Adalah data yang diperoleh langsung dari lokasi pariwisata melalui pengamatan lapangan.

b. Data Sekunder

Adalah data yang dilakukan secara langsung melalui dokumentasi data diri buku literature yang berkaitan.

\subsection{Metode Penyusunan penelitian}

Teknik yang digunakan untuk menyusun Penelitian ini adalah :

a. Observasi ( Pengamatan langsung )

Suatu metode pengumpulan data dengan melakukan pengamatan dan dokumentasi.

b. Studi Pustaka.

Mempelajari buku-buku literature dan hasil dari penelitian yang berkaitan.

\subsection{Metode Pengumpulan Data}

Algoritma Dijkstra bertujuan untuk mencari rute terpendek berdasarkan bobot terkecil dari satu koordinat ke koordinat lain. Misalkan lingkaran mengambarkan tempat wisata dan garis menggambarkan jalan, maka algoritma Dijkstra melakukan kalkulasi terhadap semua kemungkinan bobot terkecil dari setiap lingkaran. Dapat di lihat terlihat gambar 3.1. 
Universitas AL Asyariah Mandar

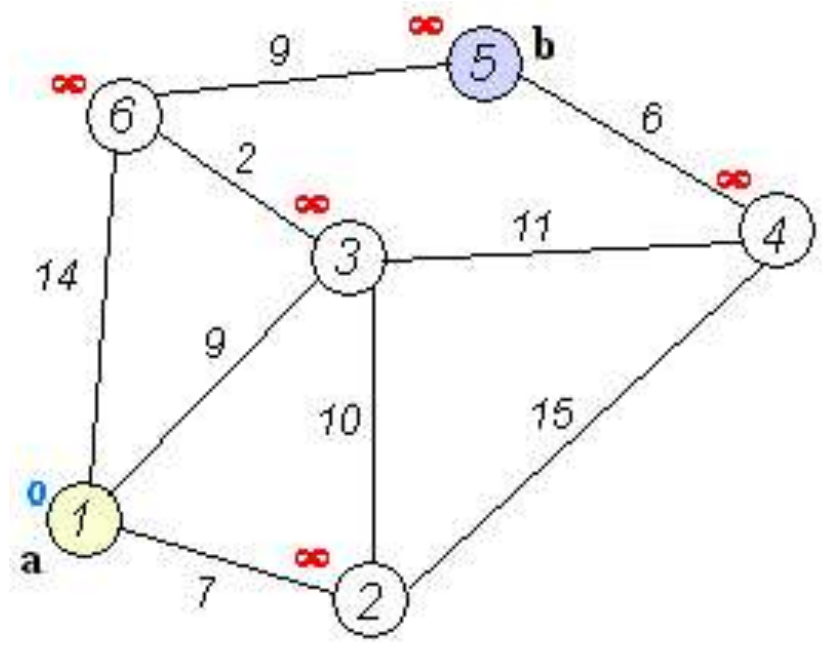

Gambar 3.1 Contoh keterhubungan algoritma Dijkstra

Algoritma Dijkstra bekerja dengan membuat jalur ke satu simpul optimal pada setiap langkahnya. Jadi pada langkah ke "n", setidaknya ada "n" node yang sudah diketahui sebagai jalur terpendek. Penjelasan langkah langkah pada algoritma Dijkstra dapat Terlihat dengan langkah-langkah berikut ini:

1. Tentukan titik mana yang akan menjadi node awal, lalu beri bobot jarak pada node pertama ke node terdekat satu per satu, Dijkstra akan melakukan pengembangan pencarian dari satu titik ke titik lain dan ke titik selanjutnya tahap demi tahap.

2. Beri nilai bobot (jarak) untuk setiap titik ke titik lainnya, lalu set nilai 0 pada node awal dan nilai tak hingga terhadap node lain (belum terisi) 2 .

3. Set semua node yang belum dilalui dan set node awal sebagai "Node keberangkatan"

4. Dari node keberangkatan, pertimbangkan node tetangga yang belum dilalui dan hitung jaraknya dari titik keberangkatan. Jika jarak ini lebih kecil dari jarak sebelumnya (yang telah terekam sebelumnya) hapus data lama, simpan ulang data jarak dengan jarak yang baru

5. Saat kita selesai mempertimbangkan setiap jarak terhadap node terdekat, tandai node yang telah dilalui sebagai "Node dilewati". Node yang dilewati tidak akan pernah di cek kembali, jarak yang disimpan adalah jarak terakhir dan yang paling minimal bobotnya.

6. Set "node belum dilewati" dengan jarak terkecil dari (node keberangkatan) sebagai "Node Keberangkatan" selanjutnya dan ulangi langkahnya hingga sampai ke note tujuan .

\section{HASIL PENELITIAN}

4.1 Pembahasan Sistem

Sistem yang akan peneliti bangun hanya akan mengelola informasi tentang wisata yang ada pada wilayah regional semarang. Pada aplikasi ini terdapat 5 halaman yaitu halaman menu, explore, favorit, maps, akun, selain itu di dalam aplikasi tersebut juga terdapat beberapa menu wisata yaitu wisata air, wisata alam, wisata sejarah, dan wisata religi dimana pengguna dapat memilih destinasi wisata sesuai kebutuhannya. Selain itu terdapat juga menu peta wisata, dimana pada menu ini pengguna dapat melihat koordinat tempat wisata yang bertujuan untuk dapat mengetahui letak koordinat wisata satu dan yang lainnya. Di dalam aplikasi ini juga terdapat menu wisata favorit yaitu adalah wisata yang di rekomendasikan untuk di kunjungi para wisatawan.

User yang baru pertama kali mengunjungi sistem akan disambut dengan halaman home wisata semarang serta pilihan wisata yang akan di kunjungi. Setelah user menentukan pilihan wisata yang akan di kunjungi maka sistem akan menampilkan profil wisata dan informasi yang terkait dengan wisata tersebut. Ketika user ingin menuju destinasi wisata tersebut maka user akan di arahkan ke peta wisata, dan akan di muncul rute perjalanan wisata dari titik awal koordinat user ke koordinat tempat wisata. User yang ingin mengunjungi lebih dari satu tempat wisata maka dapat melihat halaman peta wisata yang sudah tersedia , dimana peta tersebut dapat memperlihatkan berbagai destinasi wisata dari yang terdekat hingga yang terjauh dari posisi user berada. Setelah user sampai pada tujuan wisatanya maka user dapat memanfaatkan fitur review untuk mengulas serta menambahkan event atau acara yang sedang berlangsung di tenpat tersebut.

\subsection{Pembahasan Sistem}

Use Case Diagram menjelaskan hubungan antara aktor dengan sistem, digunakan untuk mengetahui fungsi apa saja yang terdapat pada sistem. (Gambar.1).

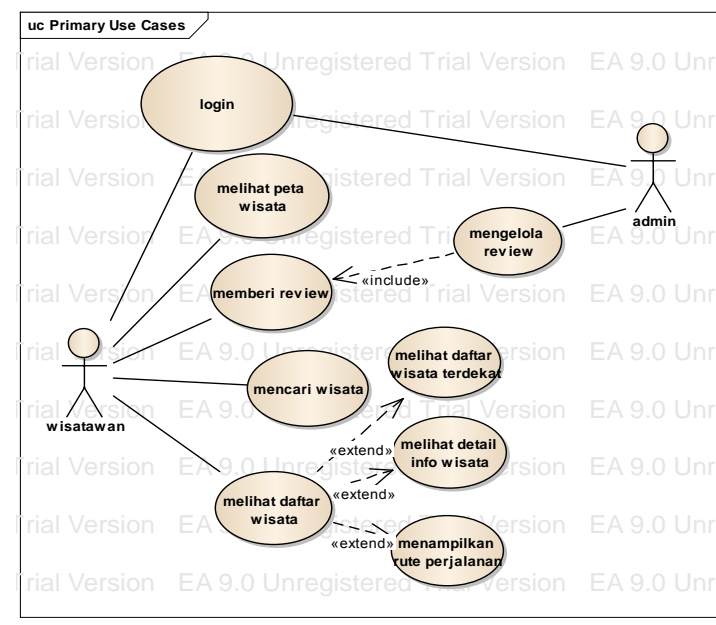

Gambar 1. Diagram Use Case 


\section{Narasi Use Case Diagram}

Pertama user akan di tunjukan halaman utama dari sistem, untuk dapat beroprasi ke dalam sistem secara lebuh lanjut user harus melakukan registrasi terlebih dahulu untuk dapat melakukan login. User dapat mencari tujuan wisata yang di inginkan untuk melakukan perjalanan wisata yang di dalamnya terdapat peta wisata, info wisata serta user juga dapat membuat review serta menambahkan ke favorit untuk wisata yang telah di kunjunginya. Jika user telah selesai melakukan aktifitas di dalam sistem, maka user dapat melakukan proses logout.

\subsection{Pembahasan Sistem}

Menampilkan seluruh menu dan isi dari aplikasi, user akan di hadapkan oleh 5 kategori (Wisata Alam, Wisata Religi, Wisata Air, Wisata Sejarah dan Wisata populer) dan 5 menu (Home, Explore, Favorit, Maps dan Akun) pada halaman utama.

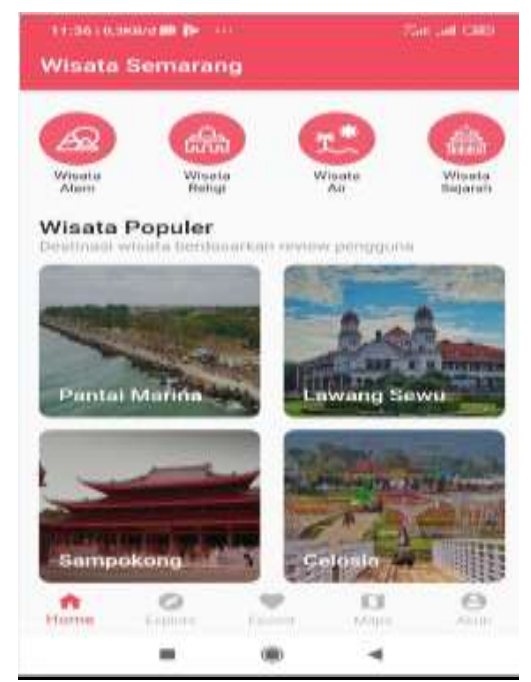

Gambar 2. Halaman Utama

1. Halaman Home

Tampilan halaman home adalah tampilan dimana user akan di lihatkan oleh tampilan awal pada sistem aplikasi, dimana tampilan ini berfungsi untuk menentukan jalannya sistem.

\section{Halaman Explore}

Halaman Explore merupakan halaman sistem dimana user dapat memilih berbagai menu wisata yaitu wisata alam, wisata religi, wisata air, wisata sejarah yang telah tersedia di dalam sistem.

\section{Halaman Favorit}

Halaman favorit adalah halaman dimana user dapat melihat rekomendasi wisata favorit yang telah di tambahkan oleh user sebelumnya yang sudah melakukan kunjungan wisata.

\section{Halaman Maps}

Halaman maps adalah sebuah halaman yang menampilkan gambar dan fungsi peta sebagai patokan user untuk melakukan kunjungan ke berbagai destinasi wisata, serta dapat di jadikan pengukur jarak antara wisata satu dan lainnya sehingga user tidak melakukan kesalahan dalam perjalannya.

5. Halaman Akun

Halaman akun adalah halaman di mana user dapat melakukan registrasi serta melakukan proses login agar dapat lebih banyak menikmati fitur dari sistem ini.

\subsection{Hasil}

Hasil penelitian dan pembahasan dilakukan untuk memeriksa apakah sistem yang telah dirancang berjalan sesuai fungsi yang diharapkan.

\section{Tabel 5.1. Pengujian Sitem}

\begin{tabular}{|c|l|l|l|}
\hline No & $\begin{array}{l}\text { Point saat } \\
\text { diuji }\end{array}$ & \multicolumn{1}{|c|}{ Pengujian } & \multicolumn{1}{|c|}{ Hasil } \\
\hline 1. & $\begin{array}{l}\text { Login yang } \\
\text { dilakukan } \\
\text { oleh } \text { User. }\end{array}$ & $\begin{array}{l}\text { Login } \\
\text { menggunaka } \\
\mathrm{n} \\
\text { username } \\
\text { dan } \\
\text { password } \\
\text { yang } \\
\text { telah } \\
\text { tersimpan } \\
\text { pada } \\
\text { database. }\end{array}$ & $\begin{array}{l}\text { Sistem dapat } \\
\text { melakukan proses } \\
\text { validasi data yang } \\
\text { telah diinput, } \\
\text { apabila data } \\
\text { belum tersimpan, } \\
\text { maka } \\
\text { sistem akan } \\
\text { menampilkan } \\
\text { pesan “email atau } \\
\text { password tidak } \\
\text { sesuai" di bawah } \\
\text { form login. }\end{array}$ \\
\hline 2. & $\begin{array}{l}\text { User } \\
\text { menambahk } \\
\text { an wisata } \\
\text { favorit. }\end{array}$ & $\begin{array}{l}\text { User dapat } \\
\text { menambahk } \\
\text { an wisata } \\
\text { favorit } \\
\text { sebagai } \\
\text { rujukan bagi } \\
\text { user lainnya. }\end{array}$ & $\begin{array}{l}\text { Sistem akan } \\
\text { memverifikasi } \\
\text { tindakan } \text { user } \\
\text { untuk } \\
\text { menambahkan } \\
\text { tempat wisata } \\
\text { yang sudah di } \\
\text { pilih ke menu } \\
\text { favorit. }\end{array}$ \\
\hline 3. & $\begin{array}{l}\text { User } \\
\text { menambahk } \\
\text { an Review. }\end{array}$ & $\begin{array}{l}\text { User dapat } \\
\text { menambahk } \\
\text { an review } \\
\text { dalam } \\
\text { bentuk text. }\end{array}$ & $\begin{array}{l}\text { Sistem akan } \\
\text { melakukan } \\
\text { verifikasi data } \\
\text { dalam bentuk text } \\
\text { yang telah di } \\
\text { kirim oleh } \text { user } \\
\text { lalu } \\
\text { menampilkannya } \\
\text { pada kolom } \\
\text { review pada } \\
\text { bagian bawah } \\
\text { menu info wisata. }\end{array}$ \\
\hline
\end{tabular}


Universitas AL Asyariah Mandar

\section{KESIMPULAN}

Sistem Pengembangan aplikasi location based service untuk informasi dan pencarian lokasi wisata di kota semarang, telah selesai dibangun sesuai dengan tujuan kegunaan untuk mempermudah wisatawan yang ingin melakukan perjalanan wisata pada wilayah kota semarang. Sistem Pengembangan aplikasi location based service untuk informasi dan pencarian lokasi wisata di kota semarang adalah sebuah sistem untuk memudahkan wisatawan dalam mencari obyek wisata di kota semarang sesuai alur sistem yang telah di buat. Di dalam sistem terdapat menu Home, Explore, Favorit, Maps dan menu Akun. Informasi yang ditampilkan oleh sistem dapat berupa text, gambar dan tampilan maps. Tujuanya agar infromasi yang di sampaikan kepada wisatawan mudah untuk di mengerti saat akan melakukan perjalanan wisata. Dengan dilengkapi fitur Aplikasi yang User Friendly, tampilan UI yang responsive, sehingga dapat menjadikan sarana pengetahuan bagi Pengguna yang meliputi semua usia, baik untuk anak-anak, remaja, dan dewasa dapat melakukan akses via Smartphone.

\section{Daftar Pustaka}

[1] M Amin, "Aplikasi Portal Informasi Pariwisata Berbasis Web Menggunakan Framework Ruby On Rails (Lokasi Kajian Sumatra Barat)" Skripsi Sarjana Universitas Sunan Gunung Djati, Bandung, 2012.

[2] Aqil Rahmatullah, "Pembuatan Sistem Informasi Pariwisata Daerah Istimewa Yogyakarta Berbasis Android" Skripsi Sarjana Universitas Gajah Mada, Yogyakarta, 2014.

[3] Brian Dani W, "Membangun Aplikasi Informasi Lokasi Pariwisata, Seni Dan Budaya Daerah Di Kabupaten Gunungkidul Berbasis Android" Skripsi Sarjana AMIKOM, Yogyakarta,2013.

[4] Rompas, B, R., "Aplikasi Location Based Service Pencarian Tempat di Kota Manado Berbasis Android." Skripsi Sarjana Jurusan Teknik Elektro-FT, UNSRAT, Manado, 2012.

[5] W. Kusuma, S. E. Mulyani, and A. Yapie, "Aplikasi Location Based Service Taman Mini Indonesia Indah (TMII) Berbasis Android," in Seminar Nasional Aplikasi Teknologi Informasi, Yogyakarta, 2013. 